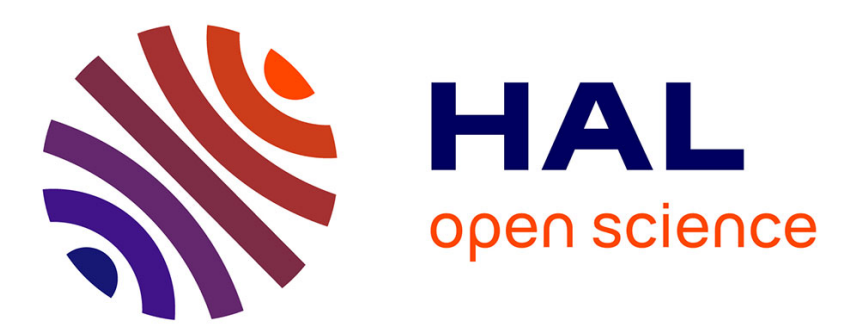

\title{
Three dimensional pole shape optimization of claw pole machines based on a hybrid model
}

\author{
Geoffrey Devornique, Julien Fontchastagner, Denis Netter, Noureddine
}

Takorabet

\section{- To cite this version:}

Geoffrey Devornique, Julien Fontchastagner, Denis Netter, Noureddine Takorabet. Three dimensional pole shape optimization of claw pole machines based on a hybrid model. International Journal of Applied Electromagnetics and Mechanics, 2018, 57 (S1), pp.73-81. 10.3233/JAE-182318 . hal-01740985

\section{HAL Id: hal-01740985 \\ https://hal.univ-lorraine.fr/hal-01740985}

Submitted on 22 Mar 2018

HAL is a multi-disciplinary open access archive for the deposit and dissemination of scientific research documents, whether they are published or not. The documents may come from teaching and research institutions in France or abroad, or from public or private research centers.
L'archive ouverte pluridisciplinaire HAL, est destinée au dépôt et à la diffusion de documents scientifiques de niveau recherche, publiés ou non, émanant des établissements d'enseignement et de recherche français ou étrangers, des laboratoires publics ou privés. 


\title{
Three Dimensional Pole Shape Optimization of Claw Pole Machines Based on a Hybrid Model
}

\author{
Geoffrey Devornique, Julien Fontchastagner, Denis Netter and Noureddine Takorabet \\ Université de Lorraine, GREEN, Vandoeuvre-lès-Nancy, France \\ noureddine.takorabet@univ-lorraine.fr
}

\begin{abstract}
This paper deals with the shape optimization of the claws of a claw-pole synchronous machine. A hybrid model combining 3D FEM and Permeance Network is developed for this purpose. The optimization of the average torque with fixed stator geometry is performed using Mesh Adaptative Direct Search methods. The developed methodology has led to improve the performances of claw-pole synchronous machines used in mild-hybrid vehicles.
\end{abstract}

Keywords: Claw-pole Synchronous machine, Optimization, 3D finite element, Coupled model, Permeance Network model

\section{Introduction}

Nowadays the progress in numerical computation methods and hardware resources suggests that optimization of magnetic devices becomes a simple task. However, some electromagnetic devices such as claw-pole machines or axial flux machines have purely three-dimensional (3D) behavior making the use of 3D finite element (FE) modeling essential. The optimization of the geometry of such devices with classical 3D FE codes requires a huge computational time (CPU time). Different contributions have been presented to avoid the use of 3D FE models and to propose either analytical or permeance network modeling in order to save CPU time [1,2]. Such methods have some weaknesses in exact geometry optimization in some areas of the machine.

An alternate approach consists in using 3D-FE models in the area of the device where the 3D FE model is really needed, and use analytical models in the other areas. The case of Claw-Pole synchronous machines used for mild-hybrid vehicles is a good example to illustrate this purpose. Indeed, the topology of the stator can be designed with any 2D model, thus we focus the study to optimize the shape of the claws for a fixed geometry and supply of the stator.

In this paper, a hybrid model combining 3D FE model for the claws and permeance network (PN) in the other areas of the machine is developed. The 3D analysis focuses on the shape of the claws. This approach strongly reduces the number of degrees of freedom (Dofs) of the problem and consequently reduces the CPU time. This model is suitable for optimization processes thanks to its fastness and robustness. Two optimization problems will be carried out on the claw-pole synchronous machine in this paper. The first problem only deals with the shape of the claws. It is used to validate the developed methodology. The second problem considers a real industrial specification which aims to reduce interpolar magnets volume while maintaining the torque specification.

\section{Hybrid Permeance Network-3D FEM Model}

As in any hybridization of two models, the general principle consists in solving physical equations (local or global) of the (magnetic) phenomena and in connecting the two models by means of interface 
conditions. Hence, in the case of a magnetostatic problem, interface conditions concern the flux conservation and the continuity of potentials. In addition, the modeling of multi-pole machines can be performed on a sector of the machine which presents magnetic and geometric periodicities. Periodic (or anti-periodic) boundary conditions can be applied in this case. Fig. 1 shows a general representation of the full 3D FE and hybrid models. In the hybrid model, Fig. 1.(b), a part of stator teeth, stator and rotor yokes and windings are modeled by PN-model while the air-gap and the claws are modeled by 3D FE model.

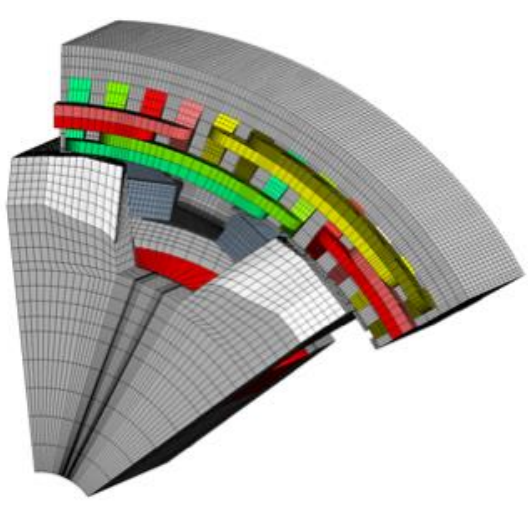

(a)

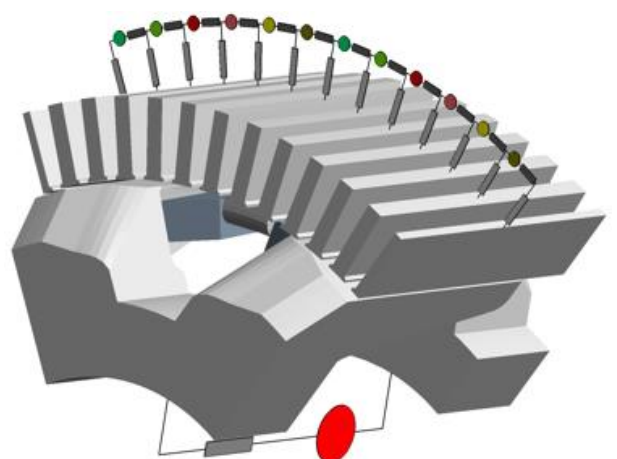

(b)

Fig. 1. General overview of full 3D and hybrid models.

In PN model, the fluxes $[\varphi]$ in the branches and magnetomotive forces $\left[V_{p}\right]$ on their terminals are defined using nonlinear permeances taking into account nonlinear $b(h)$ curves of stator and rotor cores. A scalar magnetic formulation is adopted for the 3D FE model which can be easily hybridized with PN model. Therefore, the hybrid model is composed by three equations:

- The variational formulation using the scalar potential $\left(U_{m}\right)$ in the FE domain $\Omega_{F E}$.

- Nonlinear circuit equations using magnetomotive forces $\left(V_{p}\right)$ in the reluctance network domain $\Omega_{\text {o }}$.

- Coupling equations at the interface $d S_{C}$ between the two domains.

It is summarized as follows:

$$
\begin{gathered}
\left\langle\mu h_{c}, \boldsymbol{g r a d}\left(U_{m}^{\prime}\right)\right\rangle_{\Omega_{F E}}-\left\langle\mu \operatorname{grad}\left(U_{m}\right), \boldsymbol{g r a d}\left(U_{m}^{\prime}\right)\right\rangle_{\Omega_{F E}}+\left\langle n \cdot b, U_{m}^{\prime}\right\rangle_{d S_{C}}=0 \\
\left\{\begin{array}{c}
\left\langle[\varphi],\left[V_{p}^{\prime}\right]\right\rangle_{\Omega_{\circ}}-\left\langle[P]\left[V_{p}\right],\left[V_{p}^{\prime}\right]\right\rangle_{\Omega_{\circ}}=0 \\
\varphi_{i}=\iint_{d S_{c_{i}}} n \cdot b d S \Rightarrow[\varphi]=\left\langle n \cdot b, U_{m}^{\prime}\right\rangle_{d S_{C}}
\end{array}\right.
\end{gathered}
$$

The free finite element software Gmsh [3] and GetDP [4] are used to implement such a formulation thanks to their flexibility and robustness. Fig. 2 shows the field maps in the FE domains of the hybrid model and the full 3D FE model which are in a very good agreement. Moreover, this kind of models provides a good approximation of the torque waveform, even for a high level of saturation as shown in Fig. 3. The CPU time is strongly reduced with this model. A detailed presentation is given in [5]. 


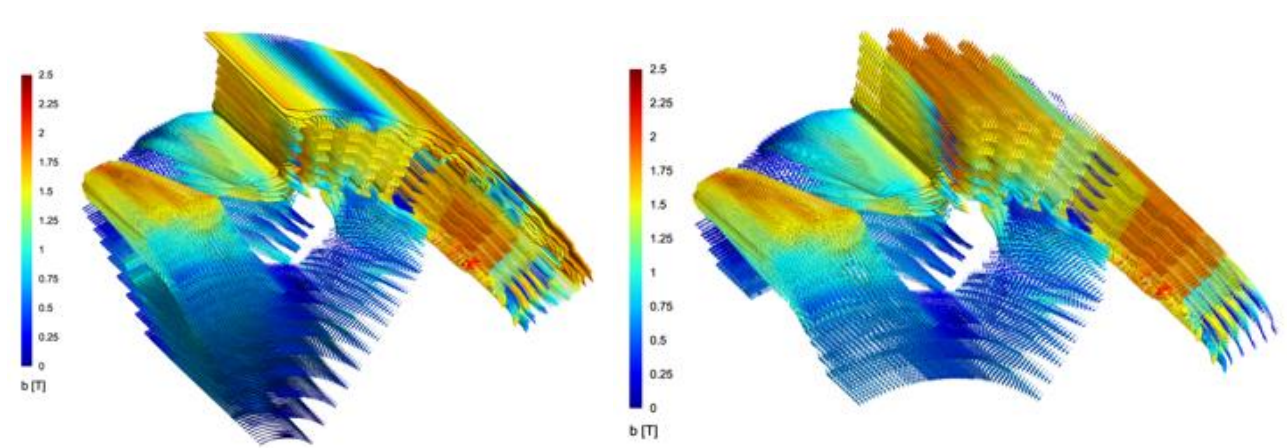

Fig. 2. Field maps at load operation: Full 3D model \& Hybrid model.

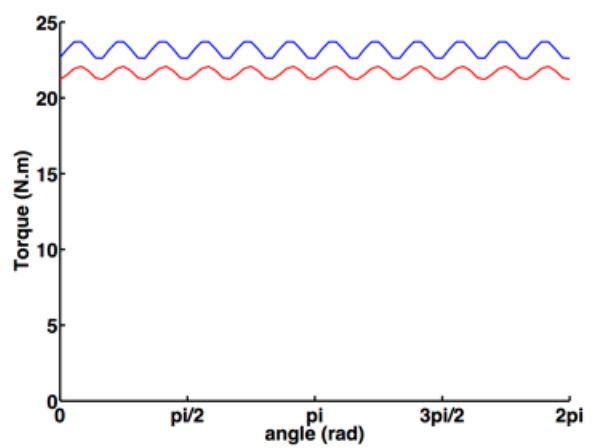

Fig. 3. Torque waveforms at load operation: Full 3D model (blue) \& Hybrid model (red) over an electrical period.

\section{Application to Claw's Shape Optimization}

In the last decade, the optimization of electromagnetic devices has known a real progress thanks to the improvement of mathematical knowledge. Many techniques have been applied to optimize the shape of electromagnetic devices with different targets $[6,7]$. However, purely $3 \mathrm{D}$ devices are not enough investigated with 3D FE models due the huge requirement in terms of CPU time. In the literature, different works have been done on this kind of machine using reluctance models in a pre-sizing process $[8,9]$. In this way, the claw shape and the general shape of the rotor are fixed according to the reluctance network definition. However, thanks to its robustness and fastness, the reluctance model can be coupled with any kind of optimization algorithm, such as genetic algorithm, particle swarm optimization, pattern search methods...

\subsection{Parametrization, and optimization problem definition}

The main idea of this work is based on the determination of an optimal claw shape, in the case of a claw-pole alternator used in mild-hybrid vehicles. First, only structures without inter-polar magnets, which can be in opposition with the actual solutions, are considered. Thus, the developed hybrid model is a good tool since it allows obtaining the average torque $T_{m}$ of the machine with a good precision in a reasonable $\mathrm{CPU}$ time for different types of claws.

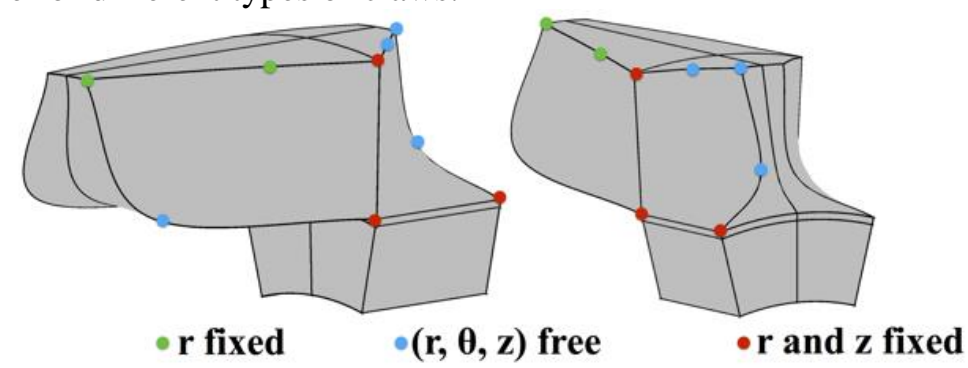

Fig. 4. Parametrization of the claw's shape 
In order to limit the complexity of the problem, $T_{m}$ is the function to be maximized for a fixed stator geometry and supply. To obtain new claw shapes, the geometry of the claw is parametrized with a set of points shown on Fig. 4, which are defined by the coordinates $(r, z)$. The surfaces of the claw are defined thanks to spline curves and segments in order to keep the symmetry and a constant air-gap during the optimization process. Moreover, some coordinates are indirectly connected to each other in order to obtain a claw that can be manufactured through an industrial process. Thus, some coordinates of geometrical points represented on Fig. 4 are the unknowns, stored in the vector $X$, of the optimization problem. These coordinates must fulfill some geometrical constraints defined by lower and upper values, $L B_{X}$ and $U B_{X}$ respectively. In this example, an optimization problem with 18 variables is performed and written as follows:

$$
\max _{X}\left(T_{m}\right) \text {, subject to: } L B_{X} \leq X \leq U B_{X}
$$

The average torque $T_{m}$ is obtained thanks to a special discretization of the mesh in the azimuthal direction along a slot pitch [10]. Thus, three positions are required to get $T_{m}$ within a less than $1 \%$ deviation compared to a finer mesh.

\subsection{Mesh Adaptative Direct Search (MADS) algorithms}

In this problem, the objectives and nonlinear constraints concern global quantities such as the torque of the electromagnetic device. These ones are encapsulated in a blackbox program with a high evaluation cost. Under these conditions, the Pattern Search class of algorithms have been selected to solve our problems. The main idea of such methods is to look for a better point than the current solution in its neighborhood defined by a given number of directions. These methods have been extended and improved, trying to globalize them by introducing some metaheuristic aspects [11,12]. A particularly interesting algorithm is a Mesh Adaptive Direct Search (MADS) developed by the GERAD research group and easily accessible through the NOMAD free software suite. Each iteration of the optimization process is divided in two main phases:

1. The Global Search: This one allows the MADS algorithm to take a meta-heuristic behavior in the optimum research phase. Meanwhile, the blackbox model is substituted by a quadratic surrogate model obtained dynamically over the iterations, and it is refined at each iteration considering all the blackbox evaluations. This surrogate model is used to try to find a better candidate far from the current iterate. All candidates are evaluated over a generated mesh following some chosen directions. A Latin Hypercube Search or a Variable Neighborhoods Search can also be added.

2. The Local Poll: It is based on a local search in a neighborhood of the current point over the current mesh defined by the directions chosen by the user. This phase allows new points to be assessed in order to improve the objective or the current constraints violation. According to the results obtained during this phase, two scenarii can occur:

- If the algorithm finds a better point, the current global mesh is centered on this point and a new phase of the MADS algorithm is performed.

- If no point improving the current solution (objective or constraints) is found, the global mesh size is decreased, and its center is not modified. If, in spite of that, the new mesh size is smaller than the user-defined size (stopping criterion), the MADS algorithm has converged.

\subsection{NOMAD implementation}

The NOMAD implementation of MADS presents different setup parameters which are necessary to adapt to the chosen optimization problem. In our case, a preliminary work has been carried out on surface mounted permanent magnet synchronous motor in order to find the right settings to reduce blackbox evaluations. Among all the methods available on the software suite, two algorithms are selected from this preliminary work: LT-MADS N+1 and ORTHO-MADS $2 \mathrm{~N}$. Their main difference lies essentially 
in the choice and the number of the search directions ( $\mathrm{N}$ correspond to the number of design variables), and in the nature of the convergence. In the first case, the convergence to an optimum is probabilistic with a probability of 1 . For the second one, the algorithm behavior is deterministic because of the orthogonality of the search directions. Details are given in $[13,14]$. These algorithms require an initial geometry. Then, in order to show the robustness of the hybrid model, and the performance of the chosen optimization method, three different starting points shown on Fig. 5, are tested.

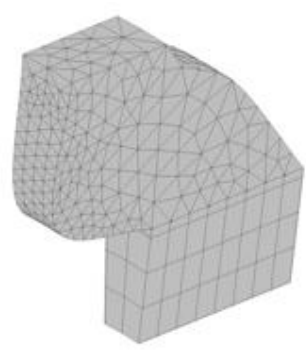

Starting Point 1

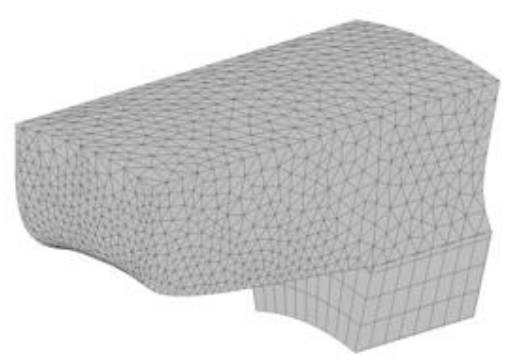

Starting Point 2

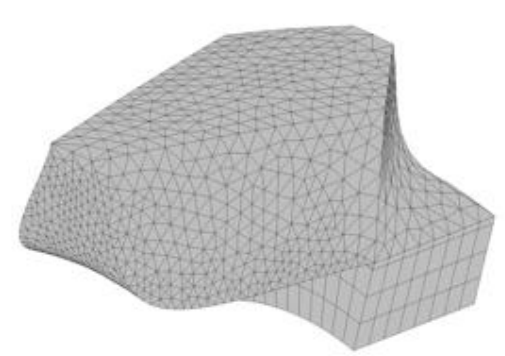

Starting Point 3

Fig. 5. The three initial geometries

\section{Preliminary Results}

The design problem corresponding to (2) is solved for each of the three starting points with both LTMADS N+1 and ORTHO-MADS $2 \mathrm{~N}$ algorithms for the same stator supply. The convergence speed depends on the initial points, as shown on Fig. 6, but the two algorithms provide quite the same value for the objective function. The relative deviation on the final value returned by both algorithms is less than $0.8 \%$.
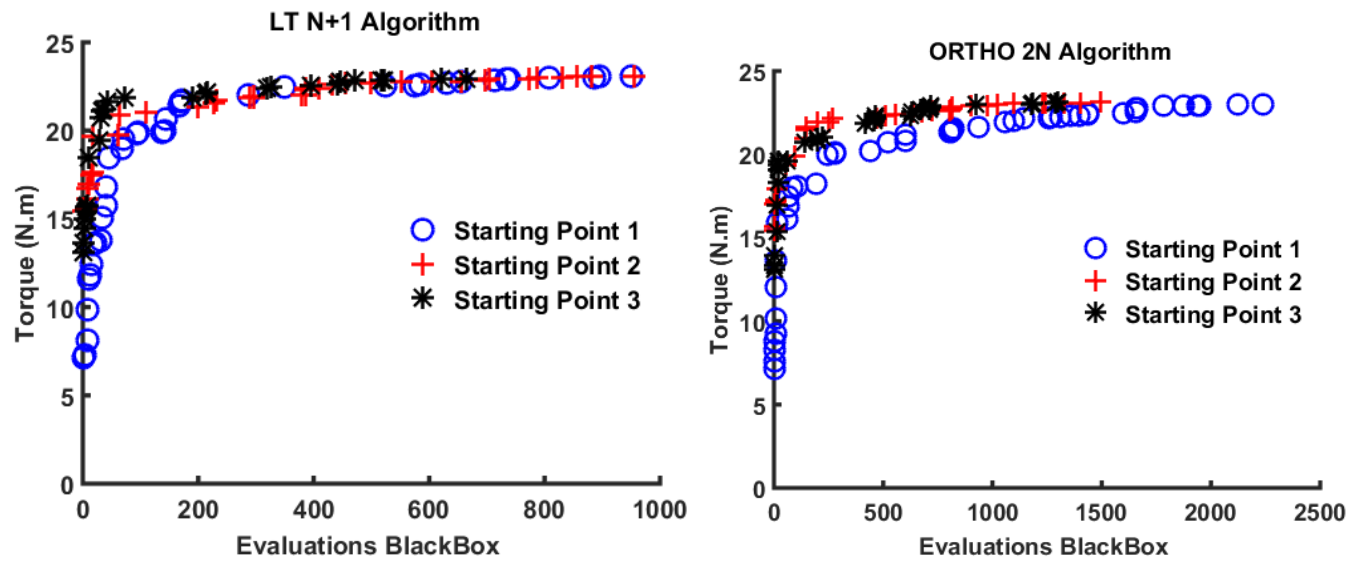

Fig. 6. Evolution of objective function during optimization processes

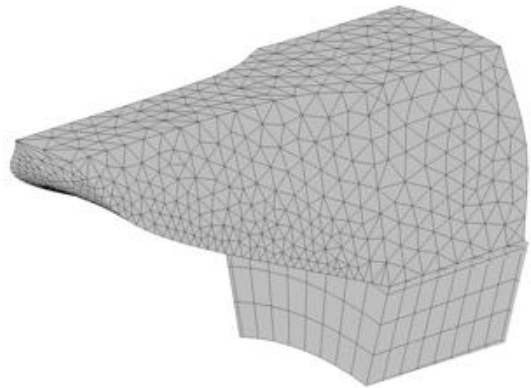

LT-MADS N+1

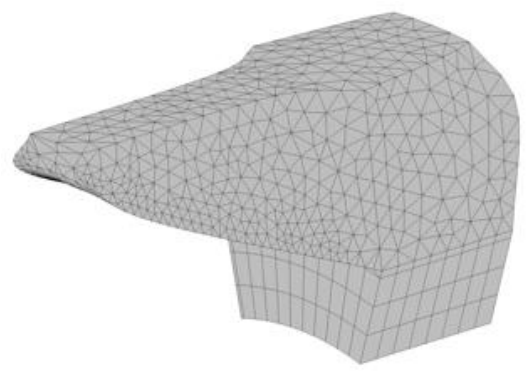

ORTHO-MADS 2N

Fig. 7. Optimal shapes of the claws obtained with the two algorithms 
The behavior of the two algorithms is almost identical for the same initial points. Nevertheless, the main difference between the two algorithms lies in the number of required calls to the objective function to obtain the optimal claw's shape. In most of the cases, the ORTHO-MADS $2 \mathrm{~N}$ algorithm needs twice more calls of the objective function than the LT-MADS N+1 algorithm. Nonetheless the six optimization problems carried out in this section confirm the robustness of the model and the method. Among the three geometries optimized for each algorithm, one per method allows maximizing the average torque. Both optimal geometries are shown on Fig. 7. Finally, the optimized geometries are quite the same for the two algorithms, but it is also interesting to compare the corresponding torque waveforms. This comparison is carried out using a magnetic vector potential formulation, applied on a whole finite element geometry of the machine. This approach allows to accurately obtain the value of the average torque and the torque ripples. Moreover, for better clarity, the curves are represented over a slot pitch, as shown on Fig. 8.

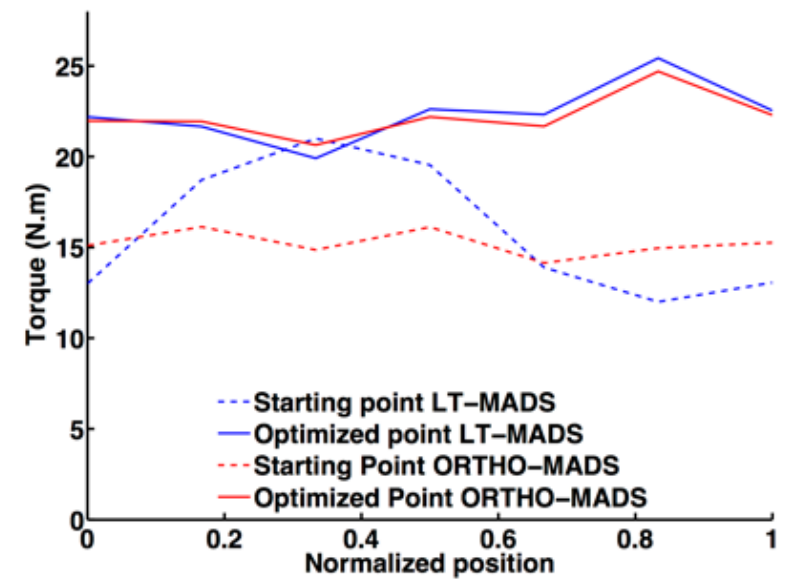

Fig. 8. Torque waveform over a slot pitch for initial geometries and corresponding optimized geometries at load operation

Despite different claw's shapes, the torque waveforms of the two optimized machines are very similar. The two algorithms used in the NOMAD suite lead to the same optimum for the design problem. However, there are some differences, especially on the value of the average torque because of the relative precision required on the global mesh size of the MADS algorithms. Some numerical details are given in Table 1 for the best optimized geometries by each algorithm.

Table 1. Numerical Data of The Two obtained Optimus

\begin{tabular}{lll}
\hline \multicolumn{1}{c}{ Algorithm } & $\begin{array}{c}\text { ORTHO- } \\
\text { MADS 2N }\end{array}$ & $\begin{array}{c}\text { LT-MADS } \\
\text { N+1 }\end{array}$ \\
\hline Initial average torque (N.m) & 13.08 & 15.43 \\
Final average torque (N.m) & 23.12 & 23.10 \\
Torque ripples (\%) & 18.28 & 24.67 \\
CPU time (s) & 128586 & 93648 \\
Function evaluations & 1413 & 956 \\
Failed evaluation (\%) & 6.44 & 6.59 \\
\hline
\end{tabular}

The performances of the optimized machines are very close in terms of average torque. Finally, the claw shape has an impact of the torque waveform but not on global value, as the average torque. Moreover, despite the presence of failed evaluations during the optimization process, both NOMAD algorithms are not disturbed, highlighting the robustness of the pre-design process. As previously noted, the LT-MADS algorithm allows to obtain an optimized solution in reduced computation times (26 hours) for a complex optimization problem. 


\section{Real industrial design case}

The methodology developed on this machine can be applied in the case of a rotor with inter-polar magnets. In this case, the geometry parametrization is modified in order to take into account the presence of magnets between the claws in a geometrical point of view as shown in Fig. 9.

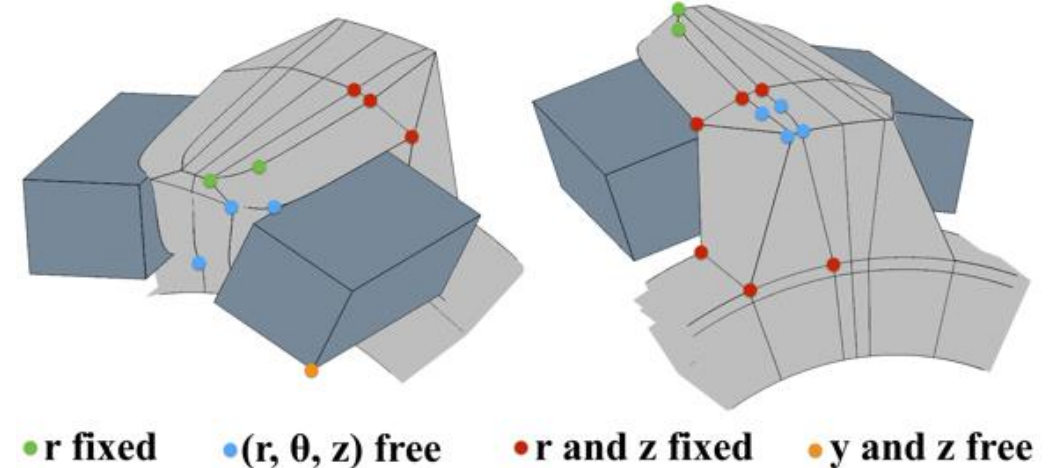

Fig. 9. Parametrization of the claw's shape with inter-polar magnets

In order to apply the previously developed methodology, 34 parameters are required. This new geometry allows applying the method described in the previous section in order to maximize the average torque $\left(T_{m}\right)$ under permanent magnets mass constraints $\left(M_{a_{0}}\right)$ or to minimize the magnets mass $\left(M_{a}\right)$ under average torque constraints $\left(T_{m_{0}}\right)$. These two problems can be written as follows:

$\max _{X}\left(T_{m}\right)$ Subject to: $\left\{\begin{array}{c}L B_{X} \leq X \leq U B_{X} \\ M_{a} \leq M_{a_{0}}\end{array}\right.$

$\min _{X}\left(M_{a}\right)$ Subject to: $\left\{\begin{array}{c}L B_{X} \leq X \leq U B_{X} \\ T_{m_{0}} \leq T_{m}\end{array}\right.$

with $T_{m_{0}}=41.68 \mathrm{~N} . \mathrm{m}$ and $M_{a_{0}}=134 \mathrm{~g}$. These data are those of a reference machine. Based on the previous results, only one starting point is used in this case. The starting and optimized geometries are shown in Fig. 10.
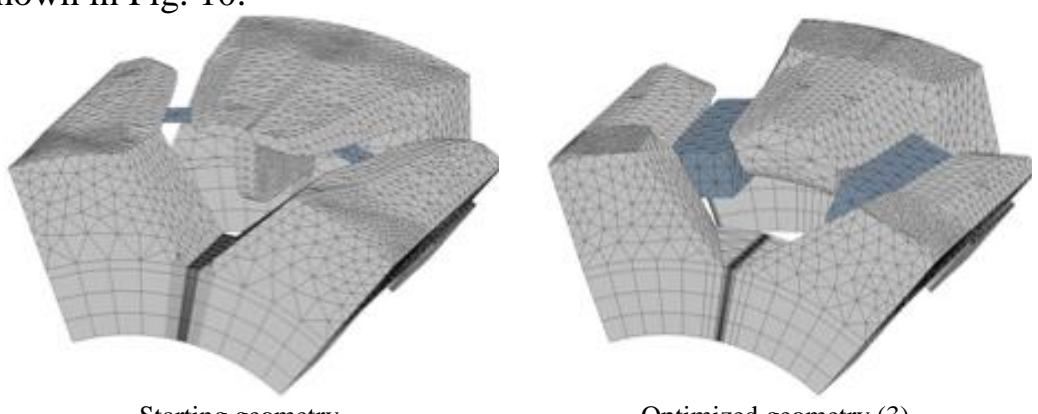

Optimized geometry (3)

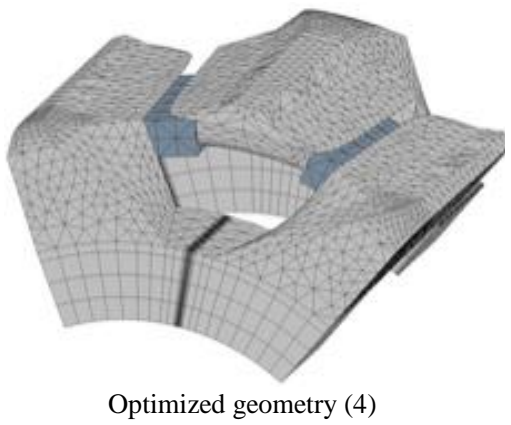

Fig. 10. Optimal shapes of the claws in the case problems (3) and (4)

The considered optimization problems can increase the performance of the initial machine or reduce the presence of rare earth magnets with constant torque. These machines are obtained using the LTMADS N+1 algorithm. Some numerical details are given in Table 2. 
Table 2. Numerical Data of The Two Constrained Problems

\begin{tabular}{lcc}
\hline & Problem (3) & Problem (4) \\
\hline Final value of objective & $47.68 \mathrm{~N} . \mathrm{m}$ & $72 \mathrm{~g}$ \\
function & $132.36 \mathrm{~g}$ & $41.68 \mathrm{~N} . \mathrm{m}$ \\
Constraint value & 3529 & 1466 \\
\hline
\end{tabular}

It can be seen on one hand, that the problem (3) allows reducing the mass of the magnets of about $45 \%$ (72 $\mathrm{g}$ instead of $134 \mathrm{~g}$ ), while maintaining the torque constant. On the other hand, the problem (4) increases the torque of about $14 \%$ while maintaining the mass of magnets constant. Therefore, the developed model and optimization methodology are efficient and can really be used in an industrial problem with realistic specifications.

\section{Conclusion}

The developed hybrid model, coupling a 3D finite element model with a permeance network, is used to evaluate the objective function in an optimization algorithm. This coupling approach allows to get a pre-design tool that optimizes claw-pole synchronous machines with and without inter-polar magnets. This pre-sizing tool can be improved by adding constraints linked with acoustic noise or thermal behavior, achieving a complete sizing tool for a claw-pole machines. A real improvement in performances of the claw-pole machines is obtained thanks to this research work.

\section{References}

[1] S. Kakugawa, N. Hino, A. Komura, M. Kitamura, H. Takeshima, T. Yatsuo and H. Tazaki, Three-dimensional optimization of correction iron pieces for open high field MRI system, IEEE Transactions on Applied Superconductivity 14 (2004), 1624-1627.

[2] A. Tan-Kim, V. Lanfranchi, J. Legranger and F. Palleschi, A hybrid electromagnetic model for acoustic optimization of claw-pole alternators, International Journal of Applied Electromagnetics and Mechanics, 51(s1) (2016), S3-S11.

[3] C. Geuzaine and J.-F. Remacle, Gmsh: a three-dimensional finite element mesh generator with built-in pre- and postprocessing facilities, International Journal for Numerical Methods in Engineering, 79 (2009), 1309-1331.

[4] P. Dular, C. Geuzaine, F. Henrotte and W. Legros, A general environment for the treatment of discrete problems and its application to the finite element method, IEEE Transactions on Magnetics, 34 (1998), 3395-3398.

[5] G. Devornique, J. Fontchastagner, D. Netter and N. Takorabet, Hybrid Model: Permeance Network and 3D finite Element for modeling Claw-Pole Synchronous Machines, IEEE Transactions on Magnetics, 53 (2017), 1-4.

[6] P. Di Barbara, M. E. Mognaschi, M. Przybylski, N. Rezasi, B. Slusarek, S. Wiak, Geometry optimization for a class of swithched-reluctance motors: A bi-objective approach, International Journal of Applied Electromagnetics and Mechanics, 56 (2017), In Press.

[7] S.-J. Kim, E.-J., Park, S.-Y. Jung, Y.-J. Kim, Optimization of the pole piece in coaxial magnetic gears for transfer torque ripple improvement, International Journal of Applied Electromagnetics and Mechanics, 55, no. 2, pp. 223-234, 2 (2017),

[8] S. Perez, Contribution au dimensionnement optimal d'alternateur à griffes sans aimant - Apport des alliages $\mathrm{FeCo}, \mathrm{PhD}$ Thesis, Institut National polytechnique de Grenoble, 2013.

[9] L. Albert, Modélisation et optimisation des alternateurs à griffes. Application au domaine automobile, PhD Thesis, Institut National polytechnique de Grenoble, 2004.

[10] Y. Hidaka and H. Igarashi, Three-dimensional shape optimization of claw-pole motors, In 2016 IEEE Conference on Electromagnetic Field Computation (CEFC), Annecy, France, Nov. 2016.

[11] M.A. Abramson, C. Audet, G. Couture, J.E. Dennis Jr., S. Le Digabel, and C. Tribes, The NOMAD project. Software available at https://www.gerad.ca/nomad/

[12] S. Le Digabel. Algorithm 909: NOMAD: Nonlinear optimization with the MADS algorithm. ACM Transactions on Mathematical Software 37 (2011), 44:1-15.

[13] C. Audet and J.E. Dennis Jr. Mesh adaptive direct search algorithms for constrained optimization. SIAM Journal on Optimization, 17 (2006), 188-217.

[14] V. Béchard, C. Audet and S. Le Digabel. Nonsmooth optimization through Mesh Adaptive Direct Search and Variable Neighborhood Search, Journal of Global Optimization, 41 (2008), 299-318. 